DEwEY, V. C. \& Kidder, G. W. (1953). J. gen. Microbiol. 9, 445-453.

\title{
Factors affecting the Requirement of Tetrahymena pyriformis (geleii) for Folic Acid
}

\author{
By VIRGINIA C. DEWEY AND G. W. KIDDER \\ Biological Laboratory, Amherst College, Amherst, Massachusetts, U.S.A.
}

SUMMARY: In the use of an organism for assay of folic acid those compounds which affect the utilization of folic acid should be determined. With Tetrahymena pyriformis (geleii), it is shown that thymine (or thymidine), glycine, $p$-aminobenzoic acid, creatin and vitamin $B_{12}$ diminish the requirement for folic acid. Pteroic acid, $p$-aminobenzoylglutamic acid, 5-methylcytosine, $p$-hydroxybenzoic acid, carbamylaspartic acid and ribonucleic acid have no effect on the requirement, while cholesterol and cortisone increase the requirement.

For some time the efforts of this laboratory have been turned toward the formulation of a technique by means of which the ciliate Tetrahymena pyriformis (geleii) (Corliss, 1952), could be utilized as a means of assay for folic acid and its conjugates. For this purpose the organism possesses a number of advantages: $(a)$ it is able to utilize either free folic acid or its polyglutamic acid conjugates with equal facility (Kidder \& Dewey, 1947); (b) it does not utilize either pteroic acid or the SLR factor (Kidder \& Fuller, 1946) in place of folic acid; (c) folic acid cannot be replaced by a mixture of purines plus thymine (Kidder, Dewey, Parks \& Heinrich, 1950). The organism shares with some bacteria the ability to grow in a medium of chemically-defined composition (Dewey, Parks \& Kidder, 1950) and the ease with which measurements of growth may be made (Kidder \& Dewey, 1948). However, in order to assay materials of plant or animal origin, it must first be determined whether or not such materials contain substances which will spare the requirement for folic acid or give non-specific stimulation. Since such materials undoubtedly contain many substances of unknown nature, one can only test a series of compounds which seem to be involved in folic acid metabolism. The presence of another member of the folic acid group, i.e. the citrovorum factor (Sauberlich \& Baumann, 1948) must also be taken into account. It has been shown that this material has an activity for $T$. pyriformis somewhat inferior to that of folic acid (Kidder, Dewey \& Parks, 1951 $a$ ). It has recently been reported that the naturally occurring citrovorum factor has an activity double that of the synthetic material (Keresztesy \& Silverman, 1951). This difference appears to be due to the fact that the synthetic material consists of a racemic mixture of which only one isomer has appreciable biological activity (Cosulich, Smith \& Broquist, 1952). On this basis it would appear that natural citrovorum factor has an activity for $T$. pyriformis about equal to that of folic acid. It has been suggested that all of the folic acid, within certain cells at least, can be accounted for as citrovorum factor (Swendseid, Bethell \& Ackermann, 1951), although later work shows that there is a fairly large amount of free folic 
acid in tissues and that both folic acid and citrovorum factor occur naturally as conjugates with glutamic acid (Wieland, Hutchings \& Williams, 1952).

The present communication deals with the ability of many compounds to diminish the requirement of $\boldsymbol{T}$. pyriformis for folic acid.

\section{MATERIALS AND METHODS}

The organism.used was Tetrahymena pyriformis (geleii) $\mathrm{W}$ in pure bacteria-free culture. It was grown in medium A (Dewey et al. 1950) containing $10 \mathrm{mg}$. Tween $80 / \mathrm{ml}$. in place of Tween 85 . Folic acid (pteroylglutamic acid) was omitted from the medium and used as a variable component as has been described previously (Kidder, Dewey \& Parks, 1951 b). The range of concentrations tested was from 0.1 to $1.0 \mathrm{~m} \mu \mathrm{g} . / \mathrm{ml}$. To the basal medium additions were made as noted in the various experiments. All the experiments were done in triplicate and repeated a number of times.

The inoculum was prepared by transferring organisms grown in $2 \%$ proteose peptone into basal medium containing $0.5 \mathrm{~m} \mu \mathrm{g}$. folic acid $/ \mathrm{ml}$. This procedure is necessary to eliminate the 'carry-over' effect (Kidder, 1946). In certain experiments the age and size of the inoculum were varied to determine the effects of these factors on growth. A standard inoculum 7-9 days old at a dilution of $1 / 200$ was used in most of the experiments. On a few occasions an inoculum grown in the complete absence (except for carry-over) of folic acid was used.

The medium was adjusted to $\mathrm{pH} 7 \cdot 0$ by means of a Beckman $\mathrm{pH}$ meter in order to protect the folic acid (the presence of Tween in the medium does not permit the accurate use of indicator dyes). Every possible effort was made to protect the media from light in order to minimize the destruction of folic acid. After inoculation the cultures were incubated in the dark at $25^{\circ}$ in a sloped position for $96 \mathrm{hr}$. Readings of the turbidity produced by the growth of the organisms were made by means of a Lumetron photoelectric colorimeter with red filter no. 650 .

\section{RESULTS}

In view of the many factors which affect the response of $T$. pyriformis to folic acid and produce variability in the results, typical experiments have been chosen to illustrate the effects of materials added to the medium. The same experiment done at different times may give somewhat different results quantitatively, although they have been repeated frequently enough to be certain of the qualitative responses.

Data obtained by varying the age of the inoculum indicate that the folic acid requirement decreases to a minimum when the inoculum is $7-9$ days old, being greater with either older or younger inocula. When inocula are less than 7 days old this may be due to the fact that the inoculum is smaller. Inocula of $1 / 500$ or 1/1000 also exhibit a larger folic acid requirement. This is not attributable to carry-over of folic acid as such in the medium, since essentially the same results are obtained using first transplant inocula grown in the absence of added folic acid (Kidder, 1946). Occasionally the older inocula failed to grow when transplanted into media containing even supra- 
optimal amounts of folic acid ( $1 \mathrm{~m} \mu \mathrm{g} . / \mathrm{ml}$.), although organisms from the same cultures grew rapidly when transplanted into proteose peptone. Folic acid has a large effect on the rate of growth of a culture of $\boldsymbol{T}$. pyriformis. Suboptimal concentrations of folic acid permit only slow growth, but the maximum yield of organisms eventually reaches nearly that attained in higher concentrations (Fig. 1). Thus it is apparent that the time at which the amount of growth is determined will have an influence on the apparent magnitude of the requirement for folic acid.

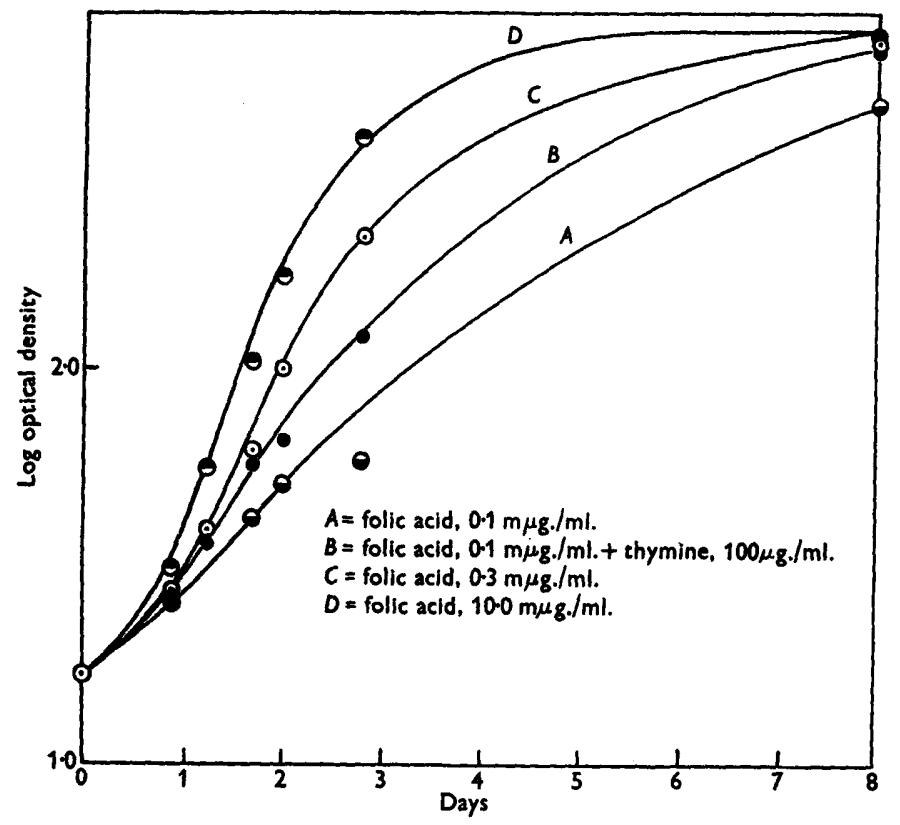

Fig. 1. Influence of folic acid and thymine on growth rate of T.pyriformis.

It was shown some years ago that folic acid could be replaced in the nutrition of Lactobacillus casei and Streptococcus faecalis by a mixture of thymine and purines (Stokstad, 1941; Snell \& Mitchell, 1941). It has already been demonstrated that $T$. pyriformis requires folic acid in addition to purines and thymine (Kidder et al. 1950), although thymine stimulates growth. Table 1 shows the degree of stimulation given by thymine in the presence of low concentrations of folic acid. It can be seen that the addition of thymine to the medium greatly increases the blank reading. This blank is quite variable and in some cases higher than half-maximal growth. Nevertheless, media which produce such growth are incapable of supporting a second transplant; this must be attributed to the sparing of folic acid carried over in the inoculum. Thymidine is even more effective than thymine in sparing folic acid and for Leuconostoc citrovorum it can replace folic acid entirely (Sauberlich, 1949). In contrast, 5-methylcytosine has no influence on the folic acid requirement of $T$. pyriformis. This compound, like cytosine, is apparently not deaminated. It seems clear that one of the functions of folic 
acid in the nutrition of $T$. pyriformis is in the synthesis of thymine or of thymidine. One of the suggested intermediates in the synthesis of pyrimidines by micro-organisms is ureidosuccinic acid (carbamylaspartic acid; Wright, Valentik, Spicer, Huff \& Skeggs, 1950). For this reason carbamylaspartic acid was tested for its ability to replace either uracil or thymine in the growth of $\boldsymbol{T}$. pyriformis. It was found to be entirely without activity. This was not entirely unexpected in view of the inactivity of orotic acid, of which ureidosuccinic acid is a precursor with Lactobacillus bulgaricus.

Table 1. The influence of thymine on the folic acid requirement of Tetrahymena pyriformis

\begin{tabular}{|c|c|c|}
\hline $\begin{array}{l}\text { Addition } \\
(\mu \mathrm{g} \cdot / \mathrm{ml} .)\end{array}$ & $\begin{array}{l}\text { Folic acid required } \\
\text { for half-maximal growth } \\
(\mathrm{m} \mu \mathrm{g} \cdot / \mathrm{ml} .)\end{array}$ & $\begin{array}{l}\text { Blank reading, } \\
\text { optical density }\end{array}$ \\
\hline None & 0.320 & 0.056 \\
\hline \multicolumn{3}{|l|}{ Thymine } \\
\hline 10 & $0 \cdot 190$ & $0 \cdot 102$ \\
\hline 20 & $0 \cdot 180$ & $0 \cdot 117$ \\
\hline 30 & 0.175 & $0 \cdot 128$ \\
\hline 40 & $0 \cdot 170$ & $0 \cdot 123$ \\
\hline Thymidir & & \\
\hline 5 & 0.075 & $0 \cdot 194$ \\
\hline
\end{tabular}

While $p$-aminobenzoic acid ( $p$-AB) forms a part of the folic acid molecule, there have been suggestions (Lampen \& Jones, 1947; Sarrett 1947) that $p$-AB has a function of its own. The effect of adding $p$-AB to media low in folic acid was tested, and it was found to increase growth slightly over that of controls

Table 2. The effect of nucleic acid derivatives on the folic acid requirement of Tetrahymena pyriformis

\begin{tabular}{|c|c|c|c|c|c|c|}
\hline \multirow{3}{*}{$\begin{array}{l}\text { Additions } \\
\text { (m/g./ml.) }\end{array}$} & & & \multicolumn{4}{|c|}{ Nucleic acid derivatives* } \\
\hline & \multicolumn{2}{|c|}{ None } & \multicolumn{2}{|c|}{ None } & \multicolumn{2}{|c|}{ Glycine and thymine $f$} \\
\hline & $a$ & $\boldsymbol{b}$ & $a$ & $\bar{b}$ & $a$ & $\bar{b}$ \\
\hline None & 0.410 & 0.056 & 0.440 & 0.062 & $\mathbf{0 . 3 1 5}$ & $0 \cdot 123$ \\
\hline \multicolumn{7}{|c|}{$p$-Aminobenzoic acid } \\
\hline $0 \cdot 1$ & 0.360 & 0.057 & 0.385 & 0.058 & 0.270 & $0 \cdot 128$ \\
\hline 0.5 & 0.320 & 0.053 & 0.296 & 0.065 & 0.250 & $0 \cdot 114$ \\
\hline 1.0 & $\mathbf{0 . 3 2 5}$ & $0 \cdot 058$ & 0.296 & 0.058 & 0.200 & $0 \cdot 127$ \\
\hline 10.0 & $\mathbf{0 \cdot 3 3 0}$ & $0 \cdot 061$ & 0.290 & 0.064 & $0 \cdot 175$ & $\mathbf{0} \cdot 128$ \\
\hline 100.0 & 0.350 & 0.059 & 0.290 & 0.068 & $0 \cdot 160$ & $0 \cdot 138$ \\
\hline
\end{tabular}

(Table 2). This effect was additive to that obtained by the addition of thymine and glycine. While the addition of the nucleotides derived from nucleic acid had no effect alone, they improved growth when added in the presence of $p$-AB. The significance of these results is not yet clear. They suggest that if $p$-AB is required, it is obtained by the breakdown of the folic acid molecule or that 
it is present as a trace contaminant of the folic acid used. It would appear that its function is not concerned with the metabolism of glycine or of the purines or pyrimidines. It is interesting that $p$-hydroxybenzoic acid is entirely inert under these conditions.

Pteroic acid ( $p$-aminobenzoylpteridine) has no sparing action on folic acid, nor has rhizopterin (SLR factor, formylpteroic acid), although both are capable of replacing folic acid in the growth of Streptococcus faecalis $\mathbf{R}$ (Stokes, Keresztesy \& Foster, 1944). Pteroic acid or SLR factor isolated from natural sources were, however, capable of replacing folic acid when used at sufficiently high levels, but this is undoubtedly due to contamination of such preparations with folic acid. On the other hand, $p$-aminobenzoylglutamic acid does not influence the folic acid requirement of $T$. pyriformis.

The work of Stekol \& Weiss (1950) and of Stekol, Weiss \& Weiss (1951) showed that the utilization of glycine as a source of labile methyl groups in mammalian nutrition is dependent on the presence of folic acid. That glycine also spares folic acid in the nutrition of $\boldsymbol{T}$. pyriformis is shown in Table 3. This may be related to the fact that serine synthesis from glycine fails except in the presence of extremely high levels of folic acid (Kidder \& Dewey, 1953). It would appear that conversion of serine to glycine is also under the control of folic acid. It may also be seen (Table 2) that the action of thymine, glycine and $p$-AB are additive.

Table 3. The influence of glycine on the folic acid requirement of Tetrahymena pyriformis

\begin{tabular}{|c|c|c|c|c|c|c|c|c|}
\hline \multirow{3}{*}{$\begin{array}{l}\text { Additions } \\
(\mu \mathrm{g} . / \mathrm{ml} .)\end{array}$} & & & \multirow{2}{*}{\multicolumn{2}{|c|}{ Thymine }} & \multicolumn{4}{|c|}{$p$-AB } \\
\hline & \multicolumn{2}{|c|}{ None } & & & \multicolumn{2}{|c|}{ None } & \multicolumn{2}{|c|}{ Thymine } \\
\hline & $a$ & $b$ & $\begin{array}{c}\text { None } \\
a\end{array}$ & $\underset{b}{p-A w}$ & $a$ & $b$ & $a$ & $b$ \\
\hline None & $\mathbf{0 . 2 6 5}$ & 0.079 & $0 \cdot 100$ & $0 \cdot 193$ & $0 \cdot 205$ & 0.114 & 0.003 & 0.847 \\
\hline \multicolumn{9}{|l|}{ Glycine } \\
\hline 10 & $0 \cdot 195$ & 0.083 & 0.090 & 0.217 & - & - & - & - \\
\hline 25 & $0 \cdot 195$ & 0.094 & 0.060 & 0.229 & - & - & - & - \\
\hline 50 & $\mathbf{0} \cdot 180$ & 0.087 & 0.045 & 0.242 & - & - & - & - \\
\hline 100 & $0 \cdot 175$ & 0.087 & 0.042 & 0.253 & 0.115 & $0 \cdot 130$ & $*$ & 0.377 \\
\hline 200 & 0.170 & $0 \cdot 100$ & 0.080 & 0.262 & - & - & - & - \\
\hline
\end{tabular}

It has been reported that the sterols, dehydroisoandrosterone and cortisone (Gaines \& Totter, 1950; Gaines \& Broquist, 1951) can replace folic acid in the nutrition of Lactobacillus casei. The effect of the addition of either cortisone or cholesterol on the response of $\boldsymbol{T}$. pyriformis to folic acid is shown in Fig. 2. While cortisone at $100 \mu \mathrm{g} . / \mathrm{ml}$. is inhibitory, lower concentrations had no effect on growth. Cholesterol was somewhat less inhibitory, and in the presence of adequate folic acid was even slightly stimulatory. The addition of glycine and thymine to the medium did not overcome the inhibitory effect of cortisone, although it did that of cholesterol. Dehydroisoandrosterone was not tested. 
A discussion of the interrelationships involving the steroid hormones, folic acid and ascorbic acid may be found in Lloyd \& Sinclair (1953).

In Table 4 are listed a number of other compounds which might possibly affect or be affected by folic acid. Betaine (Dubnoff, 1949) and formate (Sakami, 1948) are known to be sources of labile methyl groups in the mammal, but it is apparent that they have little, if any, effect on the folic acid requirement of $\boldsymbol{T}$. pyriformis. It has been noted that excess creatin is excreted by

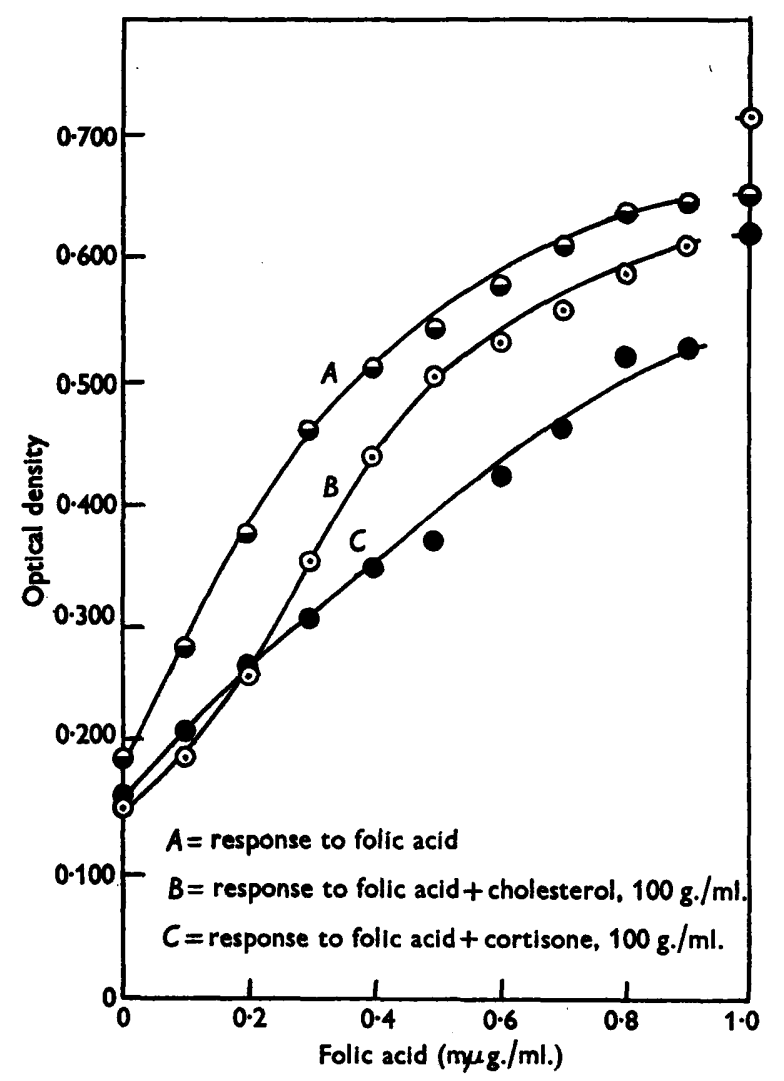

Fig. 2: Influence of sterols on response of $T$. pyriformis to folic acid.

the monkey in folic acid deficiency (Dinning \& Day, 1949). Since creatin is a methylated compound it might spare folic acid in transmethylation reactions. This may, indeed, be the explanation of the slight sparing effect exhibited by creatin. Vitamin $B_{12}$ is believed to function in the synthesis of thymidine (Wright, Skeggs \& Huff, 1948) or other deoxyribosides (Skeggs, Spizizen \& Wright, 1950), and it is, therefore, to be expected that it might function also in the sparing of folic acid. This action was noted (Table 4).

The ability of preparations of ribonucleic acid (RNA) to spare folic acid and at high levels even to replace it, can be shown to be due to the presence of folic acid as a contaminant. Purification of commercial samples of RNA by 
repeated reprecipitation with ethanol or with acid gave material which had no sparing effect on folic acid. Similar treatment of commercial deoxyribonucleic acid (DNA) was not successful in removing the activity, but purer samples isolated in the laboratory gave results which could be explained solely on the basis of the thymidine content of DNA. It seems probable that the reported ability of $T$. pyriformis to grow in the absence of certain vitamins (Elliott, 1950; Seaman, 1953) can be attributed to the use of contaminated RNA in the medium.

Table 4. Comparison of effects of various compounds on the folic acid requirement of Tetrahymena pyriformis

\begin{tabular}{|c|c|c|c|}
\hline $\begin{array}{l}\text { Addition } \\
(\mu \mathrm{g} \cdot / \mathrm{ml} .)\end{array}$ & $\begin{array}{c}\text { Folic acid } \\
\text { required for } \\
\text { half-maximal } \\
\text { growth } \\
\text { (m } \mu \mathrm{g} \cdot / \mathrm{ml} .)\end{array}$ & $\begin{array}{c}\text { Blank } \\
\text { reading, } \\
\text { optical } \\
\text { density }\end{array}$ & $\begin{array}{l}\text { Maximum } \\
\text { reading, } \\
\text { optical } \\
\text { density }\end{array}$ \\
\hline None & 0.214 & 0.086 & 0.626 \\
\hline Betaine, $\mathbf{4 0}$ & $\mathbf{0 . 2 3 0}$ & 0.095 & $0 \cdot 600$ \\
\hline Cholesterol, 10 & 0.245 & 0.085 & $\mathbf{0 . 5 8 5}$ \\
\hline Haemin, 10 & $0 \cdot 288$ & $0 \cdot 148$ & $0 \cdot 620$ \\
\hline Formate, 100 & $0 \cdot 190$ & $0 \cdot 102$ & 0.581 \\
\hline Creatin, 40 & $0 \cdot 155$ & $0 \cdot 110$ & 0.591 \\
\hline Glycine, 100 & $0 \cdot 140$ & $0 \cdot 100$ & 0.623 \\
\hline Thymine, 40 & $0 \cdot 065$ & $0 \cdot 238$ & $0 \cdot 629$ \\
\hline Glycine, 100 ; thymine, 40 & 0.040 & 0.251 & 0.585 \\
\hline $\begin{array}{l}\text { None } \\
\text { Vitamin } B_{12,} 0.001\end{array}$ & $\begin{array}{l}0 \cdot 143 \\
0 \cdot 086\end{array}$ & $\begin{array}{l}0 \cdot 118 \\
0 \cdot 154\end{array}$ & $\begin{array}{l}0 \cdot 614 \\
0 \cdot 617\end{array}$ \\
\hline
\end{tabular}

In order to perform assays for folic acid, its conjugates or citrovorum factor, by the use of $T$. pyriformis, it would be necessary to include in the medium all of the substances mentioned above which have shown a sparing effect, and to prepare an inoculum which would give a low blank reading without decreased vitality. On the other hand, since $T$. pyriformis exhibits a typical animal pattern in its folic acid nutrition, as well as in other respects, assays in the basal medium would give results indicative of the total folic acid activity of the material assayed. One major difference between the ciliate and the mammal lies in the inability of $\boldsymbol{T}$. pyriformis to transmethylate homocysteine (Genghof, 1949), a reaction which is influenced by folic acid. Another major difference is the inability of the mammal to utilize exogenous thymine (Plentl \& Schoenheimer, 1944). This discrepancy can be readily overcome by the inclusion of thymine in the assay medium. The main advantages of the use of $T$. pyriformis rather than the various lactobacilli for folic acid assays lies in the ability of the ciliate to utilize conjugates of folic acid without previous digestion. Bacterial assays would still be necessary in order to differentiate between folic acid and the citrovorum factor.

The only naturally occurring compound which will replace folic acid in the nutrition of $T$. pyriformis is the citrovorum factor (5-formyl-5:6:7:8-tetrahydropteroylglutamic acid) or the conjugates of these compounds. The earlier report (Kidder et al. 1951a) that aminopterin could replace folic acid for growth was due to gross contamination of the sample of aminopterin used 
with folic acid (Heinrich, Dewey \& Kidder, 1953). It seems probable that other folic acid analogues which promote growth of $T$. pyriformis are also contaminated.

This work was aided by grants from the Research Corporation and from the American Cancer Society recommended by the Committee on Growth. We gratefully acknowledge gifts of folic acid and pteroic acid from the Lederle Laboratories, Pearl River, New York; carbamylaspartic acid from Dr D. Sprinson, Columbia University, New York City, New York; thymidine from Dr E. E. Snell, University of Texas, Austin, Texas. Dr R. E. Parks, Jr., participated in the early phases of this work.

\section{REFERENCES}

Coruss, J. O. (1952). Comparative studies on holotrichous ciliates in the ColpidiumGlaucoma-Leucophrys-Tetrahymena group. I. General considerations and history of strains in pure culture. Trans. Amer. micr. Soc. 71, 159.

Cosulich, D. B., Smrth, J. M. JR. \& Broquist, H. P. (1952). Diastereoisomerism of leucovorin. J. Amer. chem. Soc. 74, 4215.

Dewey, V. C., Parks, R. E. Jr. \& Kidder, G. W. (1950). Growth responses of Tetrahymena geleii to changes in the basal medium. Arch. Biochem. 29, 281.

Dinning, J. S. \& DAY, P. L. (1949). Creatinuria during recovery from Aminopterin induced folic acid deficiency in the monkey. J. biol. Chem. 181, 897 .

Dusnoff, J. (1949). The role of choline oxidase in labilizing choline methyl. Arch. Biochem. 24, 251.

EuLioT, A. M. (1950). The growth-factor requirements of Tetrahymena geleii E. Physiol. Zoöl. 23, 85.

Gaines, D. S. \& Broquist, H. (1951). Microbial activity of cortisone acetate. Fed. Proc. 10, 186.

Gaines, D. S. \& Totren, J. R. (1950). Pteroylglutamic acid-like effect of dehydroisoandrosterone on growth of certain microorganisms. Proc. Soc. exp. Biol., N.Y. 74, 558.

GenghoF, D. S. (1949). The sulfur amino acid requirements of Tetrahymena geleii. Arch. Biochem. 23, 85.

Hetnrich, M. R., DeWey, V. C. \& Kidder, G. W. (1953). Ion exchange in chromatography of pteroylglutamic acid and Aminopterin. J. Amer. chem. Soc. (In the Press.)

Krefesztesy, J. C. \& Silverman, M. (1951). Crystalline citrovorum factor from liver. J. Amer. chem. Soc. 73, 5510.

KmDER, G. W. (1946). Studies on the biochemistry of Tetrahymena. VI. Folic acid as a growth factor for $\boldsymbol{T}$. geleii W. Arch. Biochem. 9, 51 .

KIDDER, G. W. \& DewEy, V. C. (1947). Studies on the biochemistry of Tetrahymena. IX. Folic acid components and conjugates. Proc. nat. Acad. Sci., Wash. 33, 95.

KrDDER, G. W. \& Dewey, V. C. (1948). Dietary factors in the utilization of homocystine. Proc. nat. Acad. Sci., Wash. 34, 81.

KIDDER, G. W. \& DEWEY, V. C. (1953). Influence of thioctic acid and folic acid on amino acid synthesis in Tetrahymena. Fed. Proc. 12, 230.

Kidder, G. W., Dewey, V. C. \& Parks, R. E. JR. (1951 a). Growth promotion in Tetrahymena by folic acid analogs. Proc. Soc. exp. Biol., N.Y. 78, 88.

Kidder, G. W., Dewey, V. C. \& Parks, R. E. Jr. (1951 b). Studies on the inorganic requirements of Tetrahymena. Physiol. Zoöl. 24, 69.

Kinder, G. W., Dewey, V. C., PArks, R. E. Jr. \& Heinrich, M. R. (1950). Further studies on the purine and pyrimidine metabolism of Tetrahymena. Proc. nat. Acad. Sci., Wash. 36, 431. 


\section{Folic acid requirement of Tetrahymena}

KmDer, G. W. \& Fuller, R. C. III (1946). The growth response of Tetrahymena geleii $\mathrm{W}$ to folic acid and to the Streptococcus lactis $\mathbf{R}$ factor. Science, 104, 160.

LAMPEN, J. O. \& Jones, M. J. (1947). The growth promoting and antisulfonamide activity of $p$-aminobenzoic acid, pteroylglutamic acid and related compounds for Lactobacillus arabinosus and Streptobacterium plantarum. J. biol. Chem. $170,133$.

LLoYd, B. B. \& Sinclatr, H. M. (1953). In Biochemistry and Physiology of Nutrition, eds Bourne, G. and Kidder, G. W. New York: Academic Press.

Plente, A. A. \& Schoenheimer, R. (1944). Studies in the metabolism of purines and pyrimidines by means of isotopic nitrogen. J. biol. Chem. 153, 203.

SARAMI, W. (1948). The conversion of formate and glycine to serine and glycogen in the intact rat. J. biol. Chem. 176, 995.

SAUBERLICH, H. E. (1949). The relationship of folic acid, vitamin $B_{12}$ and thymidine in the nutrition of Leuconostoc citrovorum 8081. Arch. Biochem. 24, 224.

Sauberitch, H. E. \& Baumann, C. A. (1948). A factor required for the growth of Leuconostoc citrovorum. J. biol. Chem. 176, 165.

SARETT, H. P. (1947). Interrelationship between $p$-aminobenzoic acid and pteroylglutamic acid as growth factors for lactobacilli. J. biol. Chem. 171, 265.

Seaman, G. R. (1953). Synthesis of B vitamins by Tetrahymena geleii S. Physiol. Zool. 26, 22.

Skrgas, H. R., Spizizen, J. \& Wright, L. D. (1950). Competitive antagonism of ribonucleic and desoxyribonucleic acids in the nutrition of Lactobacillus bifidus. J. Amer. chem. Soc. 72, 811.

SNell, E. E. \& Mrtchell, H. K. (1941). Purine and pyramidine bases as growth substances for lactic acid bacteria. Proc. nat. Acad. Sci., Wash. 27, 1.

Stekol, J. A. \& Weiss, K. (1950). Vitamin $B_{12}$ and growth of rats on diets free of methionine and choline. J. biol. Chem. 186, 343.

Strekol, J. A., Weiss, K. \& Weiss, J. (1951). Role of folacine and vitamin $B_{19}$ in synthesis and utilization of choline by the rat as studied with $\mathrm{C}^{14}$-glycine, formate and methionine. Fed. Proc. 10, 343.

Stokes, J. L., Keresztesy, J. C. \& Foster, J. W. (1944). Relation of the Streptococcus lactis $\mathbf{R}$ factor to 'folic acid". Science, $100,522$.

STokstad, E. L. R. (1941). Isolation of a nucleotide essential for the growth of Lactobacillus casei. J. biol. Chem. 139, 475.

SWendsem, M. E., Bethell, F. H. \& Ackermann, W. W. (1951). The intracellular distribution of vitamin $B_{12}$ and folinic acid in mouse liver. J. biol. Chem. $190,791$.

Wreland, O. P., Hutchings, B. L. \& Wiluiams, J. H. (1952). Studies on the natural occurrence of folic acid and the citrovorum factor. Arch. Biochem. Biophys. 40, 205.

Wright, L. D., Skegas, H. R. \& HuFf, J. W. (1948). The ability of thymidine to replace vitamin $B_{12}$ as a growth factor for certain lactobacilli. J. biol. Chem. $175,475$.

Wright, L. D., Valentik, K. A., Spicer, D. S., Huff, J. W. \& Skeggs, H. R. (1950). Orotic acid and related compounds in the nutrition of Lactobacillus bulgaricus 09. Proc. Soc. exp. Biol., N.Y. 75, 293.

(Received 26 May 1953) 